\title{
Response Surface Optimized Ultrasonic Assisted Extraction of Total Flavonoids from QingLi Cao and In Vitro Antioxidant Activities
}

\author{
Xudong Jiang ${ }^{1}$, YaoLing Liao ${ }^{1}$, GuiXi $\mathrm{Lu}^{1}$ and Zhike Xiao ${ }^{2}$ \\ ${ }^{1}$ School of Medicine, Guangxi University of Science and Technology, Liuzhou, 545005, China \\ ${ }^{2}$ Liuzhou WanYou Pest Control Research Institute, Liuzhou, 545616, China
}

\begin{abstract}
An ultrasound-assisted extraction technique was used to extract the total flavonoids from QingLi Cao. The optimal conditions were ethanol concentration $59.20 \%$, liquid-to-solid ratio $31.15 \mathrm{~mL} / \mathrm{g}$, extraction time $57.42 \mathrm{~min}$ and extraction temperature $58.57^{\circ} \mathrm{C}$, which were determined using response surface methodology. The antioxidant activities including reducing power, ABTS+, DPPH, superoxide anion and hydroxyl radical were evaluated, which suggested significant antioxidant activities.
\end{abstract}

Keywords: Antioxidant, flavonoids, Qing Li Cao, response surface methodology, Ultrasound-assisted extraction.

\section{INTRODUCTION}

QingLi Cao, a traditional herb has been used for eczema and itching in the minority of Guangxi province, China. It is distributed in Guangxi province and Vietnam. The previous studies show that the extracts are rich in flavonoids, which have been associated with their antioxidant activities. However, insufficient studies have been conducted on flavonoids from QingLi Cao and its antioxidant activity [1].

Ultrasound-assisted extraction (UAE) is an efficient and simple extraction technique. Response surface methodology (RSM) is an effective statistical method for optimizing experimental conditions and investigation of critical processes [2].

The objective of this study was to use RSM to optimize the UAE of total flavonoids from QingLi Cao and evaluate its antioxidant activities. The information obtained will be helpful to further utilization of QingLi Cao.

\section{EXPERIMENTAL}

\subsection{Chemicals and Reagents}

2,2'-Azino-bis(3-ethylbenzothiazoline-6-sulfonic acid) diammonium salt (ABTS) (Ruibio, Germany), 1,1,1-Tris (hydroxymethyl) ethane (Tris) (Amresco, USA), 1,1Diphenyl-1 -picrylhydrazyl (DPPH) (TCI, Japan). The others used purchased from Sinopharm Chemical Reagent Co., Ltd (SCRC, China) and Xiya Reagent Co., Ltd (Xiya, China) used without further purification.

*Address correspondence to this author at the School of Medicine, Guangxi University of Science and Technology, Liuzhou, 545005, China;

E-mail: okhbz@yahoo.com

\subsection{Sample Preparation}

The QingLi Cao was collected from the Qinzhou City of Guangxi Province in November 2013 and authenticated by Prof. Guangwei Huang. It was dried under shade and ground to powder (40 meshes) in a grinding mill. The powder was kept in refrigerator at $0 \sim 5^{\circ} \mathrm{C}$ until use.

\subsection{Ultrasound-Assisted Extraction of Flavonoids}

The dried powder of QingLi Cao was mixed with ethanol, and the extraction process used an ultrasonic device according to the method described in references [3]. The sample was centrifuged at $3500 \mathrm{rpm}$ for $10 \mathrm{~min}$ to collect the supernatant, UV-Vis analyzed the diluted solution. The UAE device was an ultrasonic device (B2200S, Branson Ultrasonics (Shanghai) Company) with $40 \mathrm{kHz}$ and $120 \mathrm{~W}$.

\subsection{Experimental Design}

RSM was employed to establish the optimum conditions for extraction parameters. A Box-Behnken experiment was employed and a four independent variable at three levels was used, including ethanol concentration (50-70\%), liquid-solid ratio $(25: 1-35: 1)$, extraction time $(40-80 \mathrm{~min})$ and extraction temperature $\left(50-70^{\circ} \mathrm{C}\right)$ Table 1.

\subsection{Determination of Total Flavonoids}

The amount of total flavonoids was measured following a previously reported method [4].

\subsection{Evaluation of Antioxidant Activity}

\subsubsection{Reducing Power}

The ability of sample to reduce ferric was determined by the method as is described [5]. 
Table 1. Factors and levels in response surface design.

\begin{tabular}{|c|c|c|c|c|}
\hline \multirow{2}{*}{ Levels } & \multicolumn{3}{|c|}{ Independent Variables } \\
\cline { 2 - 5 } & A & B Concentration / \% & C & Temperature $/{ }^{\circ} \mathbf{C}$ \\
Liquid-Solid Ratio / mL/g & 50 & 50 & 40 \\
\hline \hline 1 & 25 & 60 & 60 & 60 \\
\hline 0 & 30 & 70 & 70 & 80 \\
\hline
\end{tabular}

\subsubsection{ABTS Radical Scavenging Activity}

Determination of the scavenging activity of ABTS radical was based on the procedure described in the study [6].

\subsubsection{DPPH Radical Scavenging Activity}

The DPPH free radical scavenging activity was determined according to the method [7].

\subsubsection{Superoxide Radical Scavenging Activity}

The scavenging ability of superoxide radical was measured by the previously described [8].

\subsubsection{Hydroxyl Radical Scavenging Activity}

The hydroxyl radical assay was according to the previously described [9].

\subsection{Statistical Analysis}

Data for antioxidant activity are expressed as mean \pm SD for analysis performed in triplicate. The mean values and standard deviation were calculated with the Excel program from Microsoft Office 2003 package.

\section{RESULTS AND DISCUSSION}

\subsection{Extraction Parameters for Flavonoids}

\subsubsection{Fitting the RSM}

The extraction yield from QingLi Cao was further optimized through the RSM approach. The experimental points were designed as shown in Table 2 . The response value in designed was the average of triplicates.

After fitting to the experimental findings, the response extraction yield of total flavonoids and test variables are related by the following second-order polynomial equation:

$\mathrm{Y}=+1.38+0.068 \mathrm{~A}+0.015 \mathrm{~B}-0.015 \mathrm{C}-0.05 \mathrm{D}-$

$0.05 \mathrm{AB}+0.04 \mathrm{AC}+0.05 \mathrm{AD}+0.16 \mathrm{BC}-0.03 \mathrm{BD}+0.07 \mathrm{CD}-$

$0.13 \mathrm{~A}^{2}-0.076 \mathrm{~B}^{2}-0.11 \mathrm{C}^{2}-0.16 \mathrm{D}^{2}$.

Table 3 indicates that the coefficient of determination RSquared is variability in the data explained. The R-Squared was 0.8658 , suggesting that a high correlation was achieved [10]. The F-value of 6.45 and Values of "Prob $>F$ " less than 0.05 indicated the model were significant.

The effects of ethanol concentration, liquid-to-solid ratio, extraction time and extraction temperature on total flavonoids extraction yield of QingLi Cao, as well as their interactions, are shown in Fig. (1).

The plots showed interaction effects of two factors on the response while other factors were kept at constant level. When the contour plots are oval, it means the interaction of two independent variables is significant [11]. According to Table 3 and Fig. (1), the interaction between extraction time and extraction temperature was significant.

\subsubsection{Verification of Predictive Model}

The optimal extraction conditions as follows: ethanol concentration $59.20 \%$, liquid-to-solid ratio $31.15 \mathrm{~mL} / \mathrm{g}$, extraction time $57.42 \mathrm{~min}$ and extraction temperature $58.57^{\circ} \mathrm{C}$. The maximum predicted yield of total flavonoids was $13.90 \mathrm{mg} / \mathrm{g}$. The mean value $(13.80 \pm 0.04 \mathrm{mg} / \mathrm{g})$ obtained from experiment which was close to the predicted result.

\subsection{Evaluation of Antioxidant Activity}

\subsubsection{Reducing Power}

The reducing power was evaluated based on the reduction of ferric to divalent iron in which the yellow color of the test solution changes to green or blue, depending on the different reducing power of each sample. Rising absorbance at $700 \mathrm{~nm}$ indicate an increase in reducing power [12].

As shown in Fig. (2), the absorbance of the concentration of $1 \mu \mathrm{g} / \mathrm{mL}$ sample and ascorbic acid were 0.106 and 0.397 but sharply increased to $0.425,0.801$ at the concentration of $10 \mu \mathrm{g} / \mathrm{mL}$, respectively. On reducing power, the extraction had significant effects with increasing concentration in the range of $1-10 \mu \mathrm{g} / \mathrm{mL}$, but compared with the contrast, the effect of sample was slight.

\subsubsection{ABTS Radical Scavenging Activity}

The abilities of extracts assayed to be scavenging the ABTS radical in comparison with ascorbic acid [13], are 
Table 2. Box-Behnken design matrix and the experimental observed responses.

\begin{tabular}{|c|c|c|c|c|c|}
\hline Run & $\begin{array}{c}\mathrm{X}_{1} / \text { Liquid-Solid Ratio } \\
(\mathrm{mL} / \mathrm{g})\end{array}$ & $\mathrm{X}_{2} /$ Concentration $(\%, \mathrm{v} / \mathrm{v})$ & $\begin{array}{c}\mathbf{X}_{3} / \text { Extraction Time } \\
\text { (min) }\end{array}$ & $\mathrm{X}_{4} /$ Temperature $\left({ }^{\circ} \mathrm{C}\right)$ & $\begin{array}{c}\text { Total Flavonoids Yield } \\
(\mathrm{mg} / \mathrm{g})\end{array}$ \\
\hline 1 & 1 & 0 & 0 & -1 & 1.19 \\
\hline 2 & 0 & 1 & 1 & 0 & 1.35 \\
\hline 3 & 0 & 0 & 0 & 0 & 1.46 \\
\hline 4 & 0 & 1 & 0 & -1 & 1.15 \\
\hline 5 & 0 & 0 & 1 & -1 & 1.11 \\
\hline 6 & -1 & 0 & 0 & 1 & 0.91 \\
\hline 7 & 0 & 0 & 0 & 0 & 1.21 \\
\hline 8 & 0 & 0 & 0 & 0 & 1.43 \\
\hline 9 & -1 & 1 & 0 & 0 & 1.19 \\
\hline 10 & 0 & 0 & -1 & -1 & 1.22 \\
\hline 11 & 1 & 1 & 0 & 0 & 1.22 \\
\hline 12 & 0 & -1 & 0 & 1 & 1.15 \\
\hline 13 & -1 & 0 & 1 & 0 & 0.94 \\
\hline 14 & 0 & -1 & 0 & -1 & 1.09 \\
\hline 15 & 0 & 0 & 0 & 0 & 1.39 \\
\hline 16 & 0 & -1 & -1 & 0 & 1.37 \\
\hline 17 & 0 & 1 & -1 & 0 & 1.09 \\
\hline 18 & 0 & -1 & 1 & 0 & 1.01 \\
\hline 19 & 0 & 1 & 0 & 1 & 1.09 \\
\hline 20 & -1 & 0 & 0 & -1 & 1.21 \\
\hline 21 & 0 & 0 & 1 & 1 & 1.15 \\
\hline 22 & 1 & 0 & -1 & 0 & 1.21 \\
\hline 23 & 1 & 0 & 0 & 1 & 1.09 \\
\hline 24 & 0 & 0 & 0 & 0 & 1.39 \\
\hline 25 & -1 & -1 & 0 & 0 & 1.03 \\
\hline 26 & 1 & 0 & 1 & 0 & 1.22 \\
\hline 27 & 0 & 0 & -1 & 1 & 0.97 \\
\hline 28 & 1 & -1 & 0 & 0 & 1.24 \\
\hline 29 & -1 & 0 & -1 & 0 & 1.09 \\
\hline
\end{tabular}

Table 3. Variance for response surface quadratic model.

\begin{tabular}{|c|c|c|c|c|c|c|}
\hline Source & Sum of Squares & Df & Mean Square & $\boldsymbol{F}$ value & $\boldsymbol{P}$ value & Significance \\
\hline \hline Model & 0.50 & 14 & 0.036000 & 6.45 & 0.0006 & significant \\
\hline A & 0.057 & 1 & 0.057000 & 10.33 & 0.0063 & \\
\hline
\end{tabular}


Table 3. contd...

\begin{tabular}{|c|c|c|c|c|c|c|}
\hline Source & Sum of Squares & Df & Mean Square & $F$ value & $P$ value & Significance \\
\hline B & 0.002408 & 1 & 0.002408 & 0.43 & 0.5211 & \\
\hline $\mathrm{C}$ & 0.0027 & 1 & 0.002700 & 0.49 & 0.4973 & \\
\hline $\mathrm{D}$ & 0.030 & 1 & 0.030000 & 5.40 & 0.0358 & \\
\hline $\mathrm{AB}$ & 0.011 & 1 & 0.011000 & 1.98 & 0.1809 & \\
\hline $\mathrm{AC}$ & 0.0064 & 1 & 0.006400 & 1.15 & 0.3014 & \\
\hline $\mathrm{AD}$ & 0.001 & 1 & 0.001000 & 1.80 & 0.2012 & \\
\hline $\mathrm{BC}$ & 0.096 & 1 & 0.096000 & 17.29 & 0.0010 & \\
\hline $\mathrm{BD}$ & 0.0036 & 1 & 0.003600 & 0.65 & 0.4344 & \\
\hline $\mathrm{CD}$ & 0.020 & 1 & 0.020000 & 3.53 & 0.0814 & \\
\hline $\mathrm{A}^{2}$ & 0.11 & 1 & 0.110000 & 19.87 & 0.0005 & \\
\hline $\mathrm{B}^{2}$ & 0.037 & 1 & 0.037000 & 6.65 & 0.0219 & \\
\hline $\mathrm{C}^{2}$ & 0.077 & 1 & 0.077000 & 13.93 & 0.0022 & \\
\hline $\mathrm{D}^{2}$ & 0.16 & 1 & 0.160000 & 29.59 & $<0.0001$ & \\
\hline Residual & 0.078 & 14 & 0.005559 & & & \\
\hline Lack of Fit & 0.040 & 10 & 0.003991 & 0.42 & 0.8782 & Not significant \\
\hline Pure Error & 0.038 & 4 & 0.009480 & & & \\
\hline Total & 0.58 & 28 & & & & \\
\hline
\end{tabular}

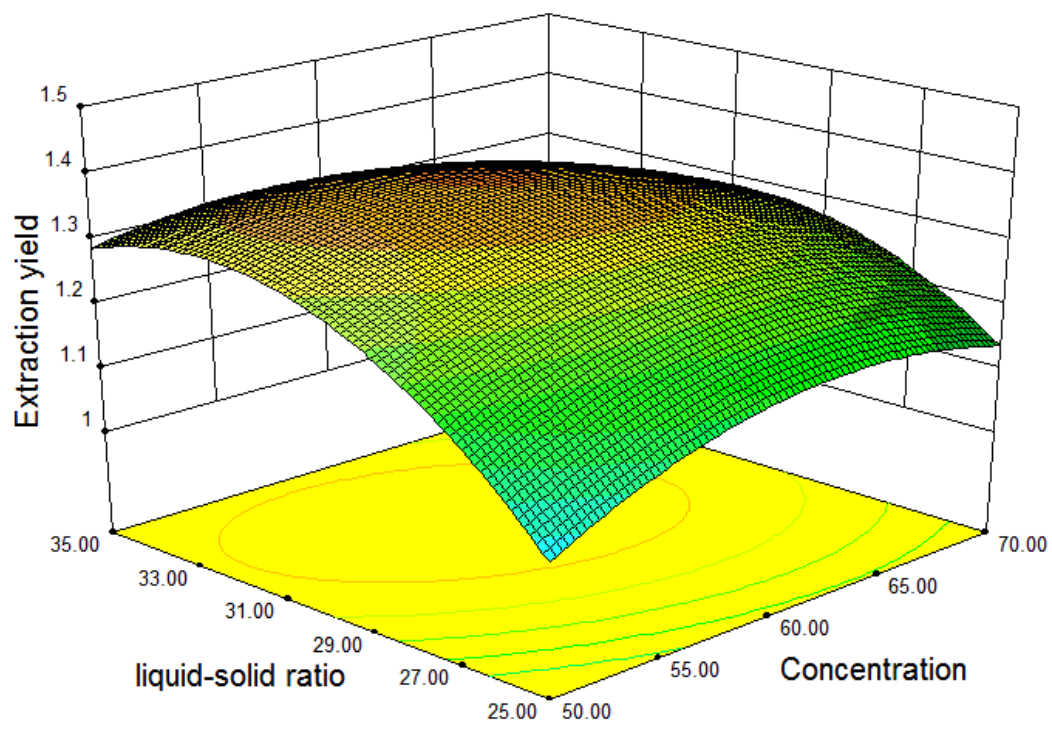

(A) Liquid-to-solid ratio and concentration

Fig. (1). Contd... 


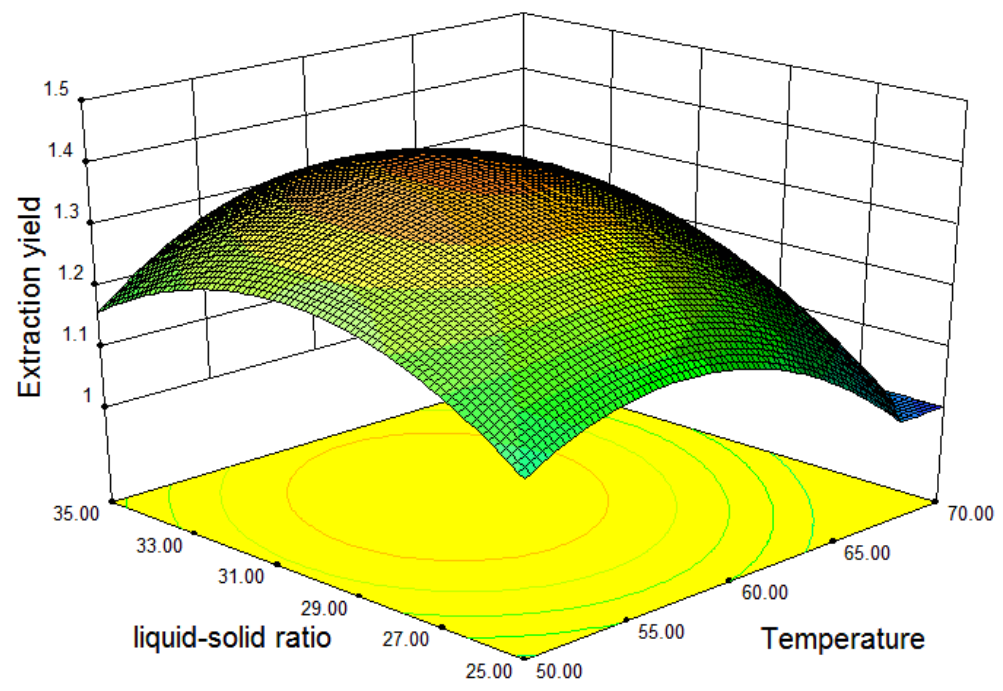

(B) Liquid-to-solid ratio and temperature

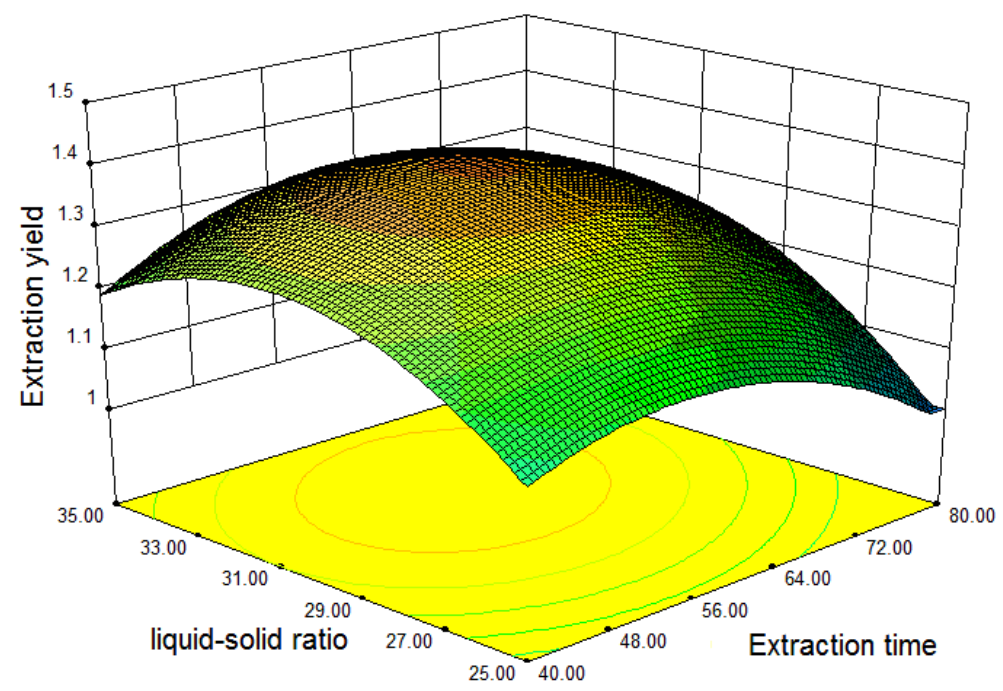

(C) Liquid-to-solid ratio and Extraction time

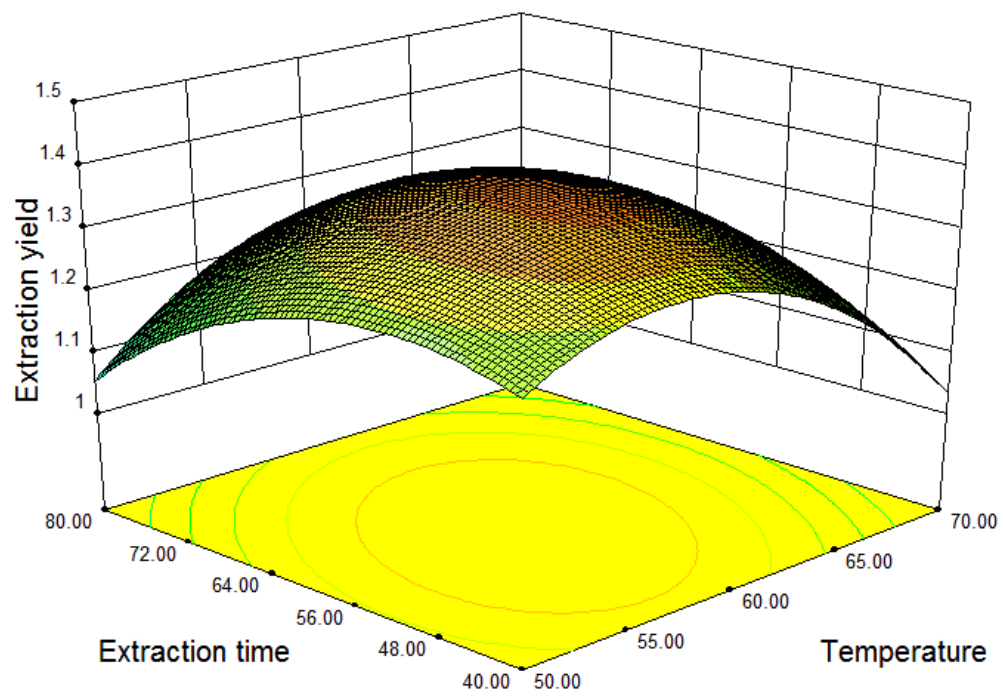

(D) Extraction time and temperature

Fig. (1). Contd... 


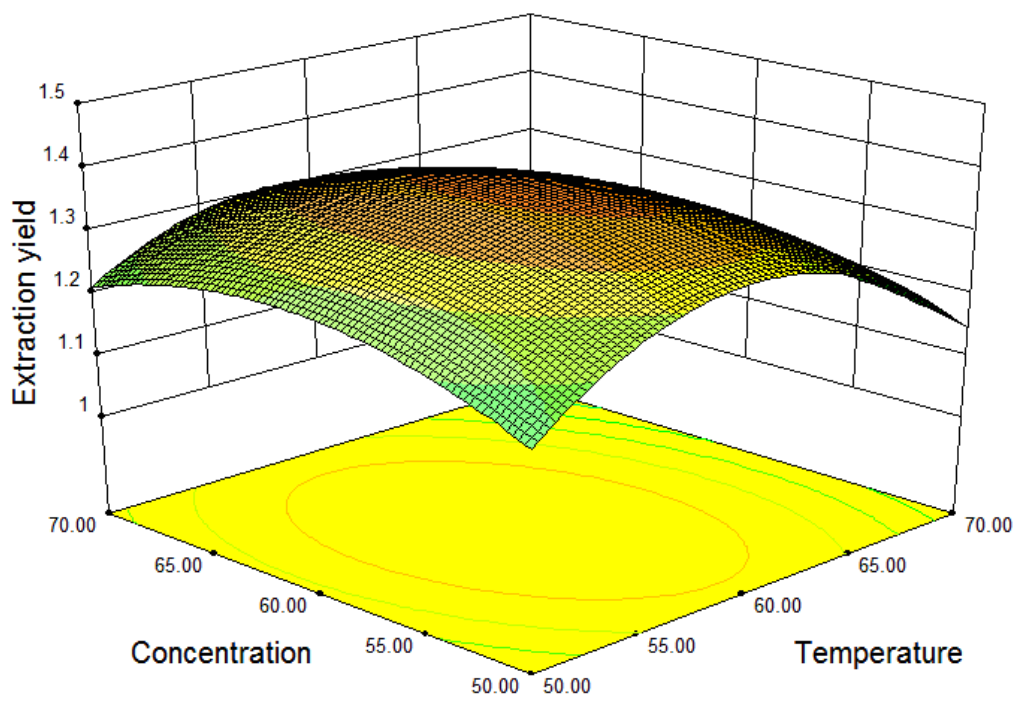

(E) Concentration and temperature

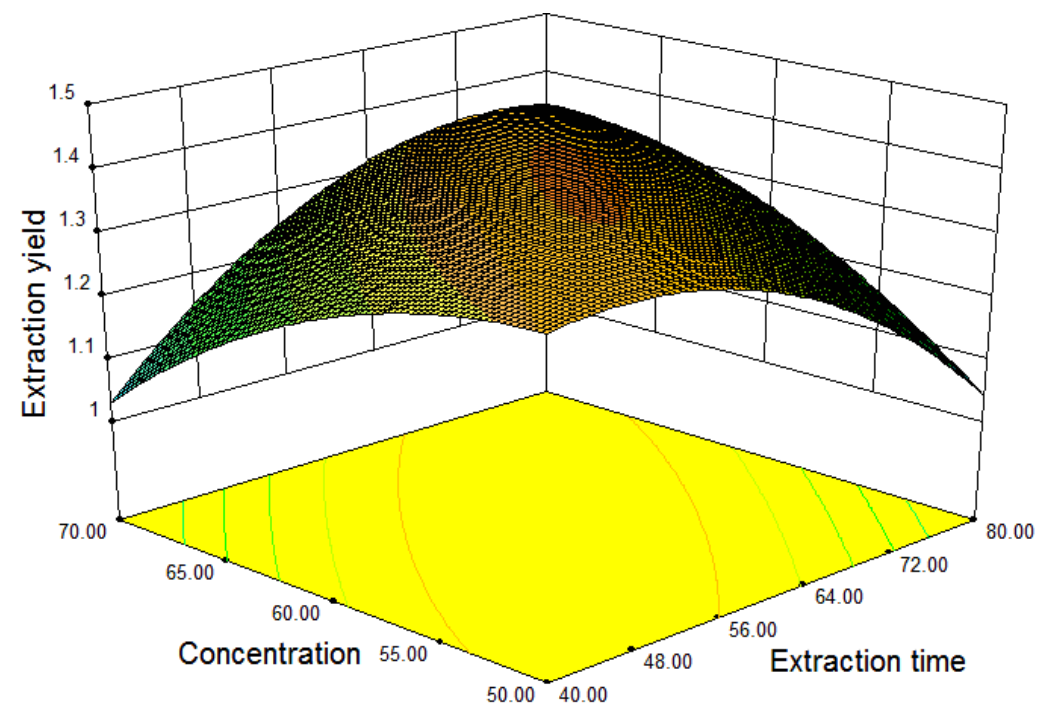

(F) Concentration and Extraction time

Fig. (1). Response surface graphs for the effects of concentration, liquid-to-solid ratio, extraction time and temperature on total flavonoids extraction yield

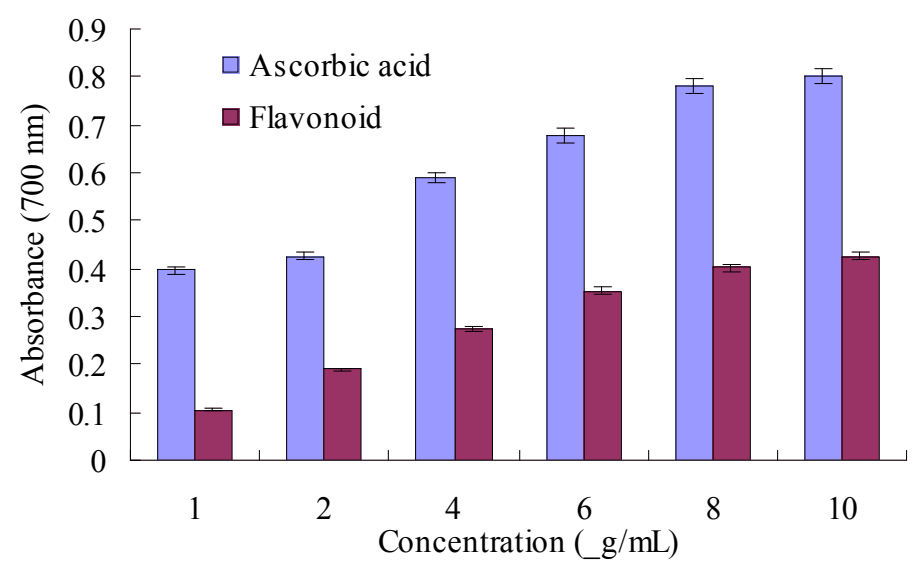

Fig. (2). Reducing power of sample and ascorbic acid. 


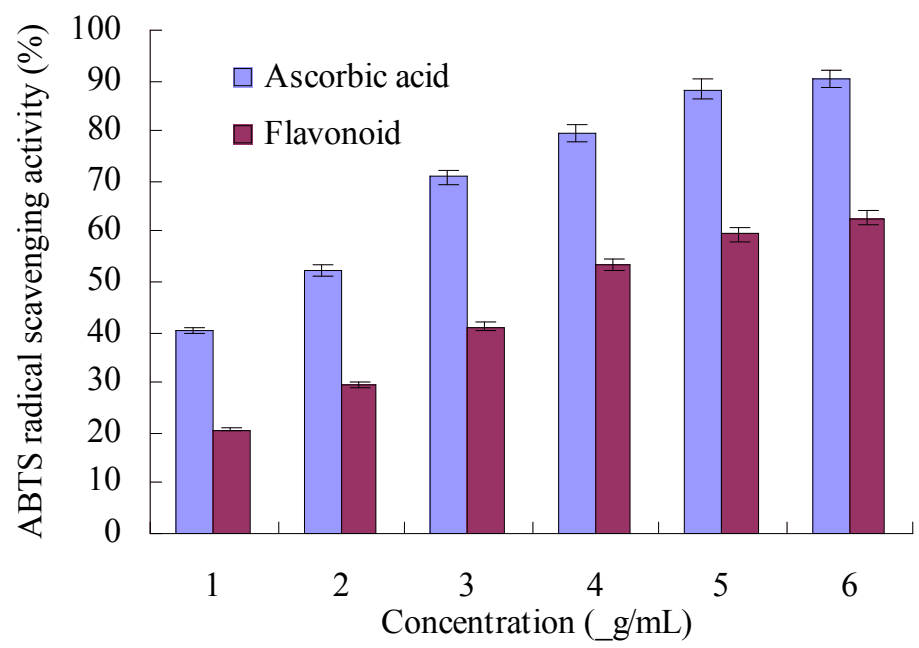

Fig. (3). ABTS radical scavenging activity of sample and ascorbic acid.

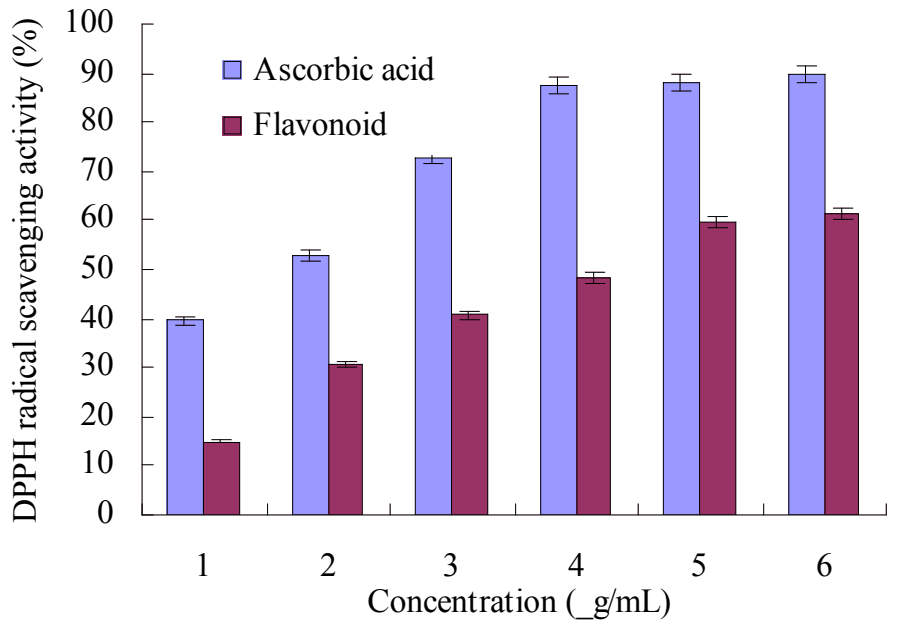

Fig. (4). DPPH radical scavenging activity of sampleand ascorbic acid.

shown in Fig. (3). The extracts had effective ABTS in a concentration-dependent manner (1 to $10 \mu \mathrm{g} / \mathrm{mL}$ ), sharply increased from $20.6 \%$ to $62.7 \%$. The scavenging effect of the contrast $(90.5 \%)$ was observed to be higher obviously.

\subsubsection{DPPH Radical Scavenging Activity}

The absorbance is decreased and the solution changes from purple to light yellow when DPPH concentration is reduced. The mechanism of scavenging DPPH radical is caused by the fact that natural compounds can transfer an electron or a hydrogen atom to DPPH [14].

In the present investigation, a comparison of sample and ascorbic acid is shown in Fig. (4). DPPH radical scavenging abilities of sample sharply increased from $15.0 \%$ to $61.3 \%$, when the concentration was increased from 1 to $10 \mu \mathrm{g} / \mathrm{mL}$. The results show that sample showed excellent percent inhibition of DPPH activity at the concentration of $10 \mu \mathrm{g} / \mathrm{mL}$ but significantly lower than that of the contrast (89.6\%).

\subsubsection{Hydroxyl Radical Scavenging Activity}

Hydroxyl radical exhibits the strongest oxidative activity in terms of its very high redox potential and extremely fast kinetics [15]. Thus, it is an important parameter for evaluating the antioxidant activity of sample extracts.

As shown in Fig. (5), hydroxyl radical scavenging effect of sample increased with concentrations. At concentration of $10 \mu \mathrm{g} / \mathrm{mL}$, it was $60.7 \%$ and $89.7 \%$ respectively for sample and ascorbic acid. Results indicated that sample had strong capability of scavenging hydroxyl radical but significantly lower than contrast.

\subsubsection{Superoxide Anion Radical Scavenging Activity}

Superoxide anion radical is considered as an initial free radical and formed from mitochondrial electron transport system [16]. 


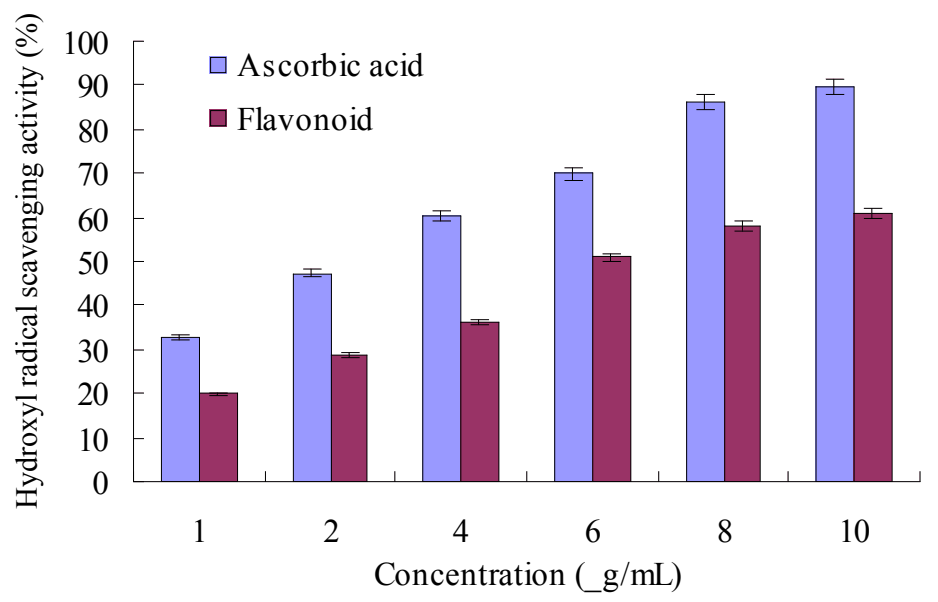

Fig. (5). Hydroxyl radical scavenging activity of sample and ascorbic acid.

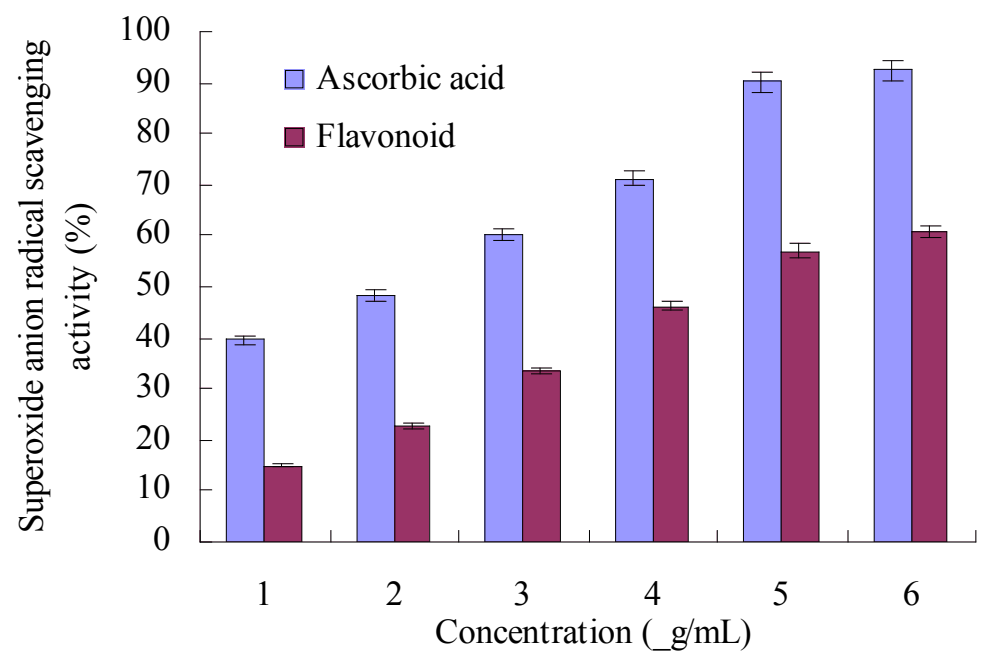

Fig. (6). Superoxide anion radical scavenging activity of sample and ascorbic acid.

Fig. (6) shows the percentage inhibition of superoxide radical generation from 1 to $10 \mu \mathrm{g} / \mathrm{mL}$ concentration of sample and ascorbic acid. In this study, superoxide anion radicals were scavenged by sample and ascorbic acid in a concentration dependent manner. The inhibition of superoxide anion radical scavenging at $10 \mu \mathrm{g} / \mathrm{mL}$ of sample was $60.7 \%$, but ascorbic acid showed stronger that is $92.4 \%$.

\section{CONCLUSION}

In this study, the RSM was successfully employed to optimize the ultrasonic-assistant extraction of total flavonoids from QingLi Cao and evaluated. The results showed that all the factors had significant effects on the extraction rate of total flavonoids. The optimum extraction conditions were obtained at ethanol concentration $59.20 \%$; liquid-to-solid ratio $31.15 \mathrm{~mL} / \mathrm{g}$; extraction time $57.42 \mathrm{~min}$ and extraction temperature $58.57^{\circ} \mathrm{C}$. The extraction rate of total flavonoids was in agreement with the predicted ones.

The antioxidant activities including reducing power, ABTS + radical scavenging activity, DPPH radical scavenging activity, superoxide anion scavenging activity and hydroxyl radical scavenging activity were evaluated, which suggested significant antioxidant activities.

\section{CONFLICT OF INTEREST}

The authors confirm that this article content has no conflict of interest.

\section{ACKNOWLEDGEMENTS}

This study was financially supported by Liu Dong New Area science and technology development plan (20120009) and Liuzhou WanYou pest control research Institute.

\section{REFERENCES}

[1] Zsuzsanna H, Ana M, Orbn-Gyapa O. Xanthine oxidase-inhibitory activity and antioxidant properties of the methanol extract and flavonoids of Artemisia asiatica. Rec Nat Prod 2014; 8: 3: 299-302.

[2] Wang XS, Wu QN, Chen GY. Response surface optimized ultrasonic-assisted extraction of flavonoids from Sparganii rhizoma and evaluation of their in vitro antioxidant activities molecules. 2012; 17: 6769-83. 
[3] Zhang $\mathrm{C}, \mathrm{Wu} \mathrm{S}, \mathrm{Xu} \mathrm{N}$. Optimization of ultrasonic-assisted extraction of polysaccharides from the stem of Actinidia arguta. Sci Technol Food Ind 2012; 33: 297-9.

[4] Mustafa O, Mustafa B, Kubilay G. Antioxidant /antiradical properties of microwave-assisted extracts of three wild edible mushrooms. Food Chem 2014; 157: 323-31.

[5] Tian F, Li B, Ji BP. Antioxidant and antimicrobial activities of consecutive extracts from Galla chinensis: The polarity affects the bioactivities. Food Chem 2009; 113: 173-9.

[6] Heo BG, Park YJ, Park YS. Anticancer and antioxidant effects of extracts from different parts of indigo plan. Ind Crops Prod 2014; 56: 9-16.

[7] Tukappa A, Londonkar RL. Evaluation of antibacterial and antioxidant activities of different methanol extract of Rumex vesicarius. L. Am J Drug Discov Dev 2013; 3: 72-83.

[8] Kannadhasan1 R, Venkataraman S. In vitro capacity and in vivo antioxidant potency of sedimental extract of Tinospora cordifolia in streptozotocin induced type 2 diabetes. Avicenna J Phytomed 2013; 3: 7-24.

[9] Chien PJ, Li CM, Lee CH. Influence of micronized chitosan on antioxidative activities in grape juice. Food Nutr Sci 2013; 4: 2248.
[10] Zheng XL, Liu BG, Li LM. Microwave-assisted extraction and antioxidant activity of total phenolic compounds from pomegranate peel. J Med Plants Res 2011; 5: 1004-11.

[11] Wang YX, Lu FX, Lu ZX. Optimization of cultivation conditions for exopolysaccharide and mycelial biomass by Clitocybe sp. using Box-Behnken design. Sci Agric Sin 2005; 1:145-50.

[12] Meir S, Kanner J, Akiri B. Total phenolic content and antioxidant activity of seed extract of Lagerstroemia speciosa. L. Chem Sci Trans 2013; 2: 75-80.

[13] Shon MY, Kim TH, Sung NJ. Antioxidants and free radical scavenging activity of Phellinus baumii (Phellinus of Hymenochaetaceae) extracts. Food Chem 2003, 82: 593-7.

[14] Sasikumar JM, Patharaj J, Adithya ES. Antioxidant capacity and phenolic content of Elaeagnus kologa schlecht. An underexploited fruit from India. Free Radicals Antioxidants 2012; 3: 28-35.

[15] Tang EL, Rajarajeswaran J, Fung SY. Antioxidant activity of Coriandrum sativum and protection against DNA damage and cancer cell migration. BMC Complement Altern Med 2013; 13: $347-54$

[16] Roginsky V, Lissi EA. Review of methods to determine chain breaking antioxidant activity in food. Food Chem 2005; 92: 23554

This is an open access article licensed under the terms of the Creative Commons Attribution Non-Commercial License (http://creativecommons.org/licenses/ by-nc/4.0/) which permits unrestricted, non-commercial use, distribution and reproduction in any medium, provided the work is properly cited. 